Published in final edited form as:

Biochemistry. 2007 February 27; 46(8): 2091-2099.

\title{
Nucleosome Recognition by the Piccolo NuA4 Histone Acetyltransferase Complext
}

\author{
Christopher E. Berndsen $\ddagger$, William Selleck§, Steven J. McBryant $\|$, Jeffrey C. Hansen II, Song \\ Tan§, and John M. Demi ${ }^{\star}, \ddagger$ \\ Department of Biomolecular Chemistry, University of Wisconsin-Madison School of Medicine and \\ Public Health, Madison, Wisconsin 53706, Center for Gene Regulation, Department of Biochemistry \\ and Molecular Biology, Pennsylvania State University, University Park, Pennsylvania 16802, and \\ Department of Molecular Biology and Biochemistry, Colorado State University, Fort Collins, \\ Colorado 80523
}

\begin{abstract}
The mechanisms by which multisubunit histone acetyltransferase (HAT) complexes recognize and perform efficient acetylation on nucleosome substrates are largely unknown. Here, we use a variety of biochemical approaches and compare histone-based substrates of increasing complexity to determine the critical components of nucleosome recognition by the MOZ, Ybf2/Sas3, Sas2, Tip60 family HAT complex, Piccolo NuA4 (picNuA4). We find the histone tails to be dispensable for binding to both nucleosomes and free histones and that the H2A, H3, and H2B tails do not influence the ability of picNuA4 to tetra-acetylate the $\mathrm{H} 4$ tail within the nucleosome. Most notably, we discovered that the histone-fold domain (HFD) regions of histones, particularly residues 21-52 of $\mathrm{H} 4$, are critical for tight binding and efficient tail acetylation. Presented evidence suggests that picNuA4 recognizes the open surface of the nucleosome on which the HFD of H4 is located. This binding mechanism serves to direct substrate access to the tails of $\mathrm{H} 4$ and $\mathrm{H} 2 \mathrm{~A}$ and allows the enzyme to be "tethered", thereby increasing the effective concentration of the histone tail and permitting successive cycles of $\mathrm{H} 4$ tail acetylation.
\end{abstract}

In eukaryotic nuclei, DNA is packaged into a complex DNA-protein macromolecule (chromatin) consisting of repeating units of histone protein wrapped by DNA. Alterations in chromatin structure, such as nucleosome sliding, removal of nucleosomes, and disruption of DNA-histone or histone-histone contacts through post-translational modification of the histones, have been linked to transcriptional regulation, DNA damage repair, and replication, among other cellular processes (1-5). Modification of histones occurs primarily in the Nterminal residues or tail region. These modifications include phosphorylation, ubiquitinylation, methylation, sumolyation, and acetylation. A major focus of chromatin research is to understand how the modification state of histones is linked to the resulting phenotype. Acetylation of histones is generally associated with active transcription, constitutes a posttranslational mark recognized by specific chromatin factors, and has been shown in vitro to prevent salt-induced folding of nucleosome arrays (6-8). Histone acetyltransferases (HATs) 1 modify histones by facilitating the transfer of the acetyl moiety from acetylcoenzyme $\mathrm{A}(\mathrm{CoA})$

\footnotetext{
†This work supported in part by NIH Grants GM059785 to J.M.D., GM45916 to J.C.H., and GM064089 to S.T.

* To whom correspondence should be addressed: University of Wisconsin-Madison School of Medicine and Public Health, 551 Medical Sciences Center, 1300 University Ave., Madison, WI 53706. Telephone: 608-265-1859. Fax: 608-262-5253. E-mail: jmdenu@wisc.edu. ¥University of Wisconsin-Madison School of Medicine and Public Health.

\$Pennsylvania State University.

|Colorado State University.

SUPPORTING INFORMATION AVAILABLE

SDS-PAGE and TAU gels of historic and nucleosomes, Esa1 saturation curves, and a H420-102 competition study. This material is available free of charge via the Internet at http://pubs.acs.org.
} 
to the $\varepsilon$-amine of lysine residues. The best studied families of HATs are the Gcn5-related $N$ acetyltransferase (GNAT) family and the MOZ, Ybf2/Sas3, Sas2, Tip60 (MYST) family (9). Members of both HAT families have been shown to acetylate histones as part of large multiprotein complexes. The subunits of HAT complexes have been proposed to target the catalytic subunit to specific loci, regulate HAT activity, and mediate nucleosome recognition $(1,10,11)$.

Esa1, the essential Sas2-related acetyltransferase in yeast, has been linked to DNA damage repair, riboprotein gene transcription, and global acetylation of H4 (12-16). Orthologues of Esa1 are reported to have similar functional roles (15). In yeast cell extracts, Esa1 co-purifies with a multiprotein complex NuA4 and separately as a trimeric complex, Piccolo NuA4 (picNuA4). The functional roles of all NuA4 subunits are not entirely known, although some are essential for yeast under normal growth conditions (15). The picNuA4 complex consists of the subunits Esa1, Epl1, and Yng2 and displays similar in vitro acetylation patterns to those of the larger NuA4 complex, which also contains the same three subunits (14). The picNuA4 complex is proposed to be responsible for global $\mathrm{H} 4$ acetylation in yeast (14).

The molecular basis for recognition of nucleosome substrates by HATs is not well-known. Crystal structures of Gcn5 and orthologue p/CAF with bound peptide substrates or bisubstrate inhibitors show numerous contacts with the peptide substrate, suggesting that recognition may be based solely on the sequence of amino acids surrounding the target lysine $(11,17,18)$. However, it was noted that some known in vivo substrates of Gcn5 and p/CAF do not conform to this model, suggesting that the other subunits of the GCN5 and p/CAF complexes may alter the specificity of the HAT (11). Because only short peptides were employed in these studies, potential interactions with native nucleosomal substrates are not known. Some models of nucleosome recognition have suggested that post-translational modifications within the histone tail influence the ability of HAT complexes to acetylate chromatin, suggesting that the histone tails themselves play an essential role in nucleosome recognition $(19,20)$. Unfortunately, the lack of knowledge on the fundamental principles that govern nucleosome recognition make predictions of binding determinants difficult.

Here, we have investigated the ability of Esa1 and the picNuA4 complex to acetylate histone substrates of increasing structural complexity, ranging from small peptides to free histones to nucleosome arrays. Most notably, we find that the histone-fold domain (HFD) of histones plays a critical role in the recognition by Esa1 and the picNuA4 complex of both free histones and histones assembled into nucleosomes. While we find that Esa1 can acetylate nucleosomes, the subunits Ep11 and Yng2 dramatically increase the stability of Esa1 and the efficiency of nucleosome recognition, consistent with previous studies that showed that particular regions of Epl1 and Yng2 play critical roles in the ability of picNuA4 to act on its nucleosome substrate (21). Nucleosomes are acetylated at rates approaching the molecular diffusion limit in aqueous solution, indicating that the picNuA4 complex contains all of the components necessary for highly efficient nucleosome recognition and acetylation. The histone tails of $\mathrm{H} 3, \mathrm{H} 2 \mathrm{~A}$, and H2B do not contribute to nucleosome recognition or the efficient acetylation of the preferred $\mathrm{H} 4$ tail. We have identified a region within the HFD of $\mathrm{H} 4$ that appears to serve as the predominant interaction site for picNuA4. Together, our results provide new insight into the mechanisms by which HAT complexes catalyze specific but processive-like acetylation on nucleosomal lysine residues. The ability of HAT complexes to utilize multiple-binding interactions on the nucleosome (e.g., tails, the HFD, and DNA) may be a general feature of highly specific and efficient catalysis shared by other chromatin-modifying enzyme complexes. 


\section{EXPERIMENTAL PROCEDURES}

\section{Materials}

Acetyl-CoA, Tris-Cl, Bis-tris, sodium acetate, dithiothreitol (DTT), and other reagents were purchased from Sigma-Aldrich or Fisher Chemicals.

\section{Enzyme Purification}

His-tagged Esa1 was prepared by expressing the recombinant enzyme in BL21(DE3)pLysS from the pETSa vector. Cells were grown in $1 \mathrm{~L}$ of $2 \times$ YT media to $\mathrm{OD}_{600}=0.5$ and then cooled to room temperature for $20 \mathrm{~min}$ before adding $0.4 \mathrm{mM}$ isopropyl-/ $\beta$-D-thiogalactopyranoside (IPTG). Cultures were induced for $4 \mathrm{~h}$, and cells were harvested by centrifugation. Cells were lysed by repeated freeze-thaw cycles, followed by sonication at $15 \mathrm{~W}$ in a buffer containing $50 \mathrm{mM}$ sodium phosphate at $\mathrm{pH} 7.5,300 \mathrm{mM} \mathrm{NaCl}, 5 \mathrm{mM} \beta$-mercaptoethanol $(\beta$ $\mathrm{ME}$ ), and $1 \mathrm{mM}$ benzamidine. Soluble protein was collected by centrifugation for $20 \mathrm{~min}$ at $14000 \mathrm{rpm}$. The supernatant was then loaded on a $5 \mathrm{~mL}$ HiTrap chelating HP column preloaded with $\mathrm{Ni}^{+}$(Amersham Biosciences). The column was washed with lysis buffer until the absorbance at $280 \mathrm{~nm}$ was less than 0.2 . The protein was eluted by a linear gradient from 0 to $200 \mathrm{mM}$ imidazole in lysis buffer. Fractions containing Esa1 as determined by sodium dodecyl sulfate-polyacrylamide gel electrophoresis (SDS-PAGE) and activity assays were pooled and concentrated to less than $10 \mathrm{~mL}$. Protein was further purified by size-exclusion chromatography on an XK-26 column packed with Sephracryl 200 (Amersham Biosciences) in $50 \mathrm{mM}$ Tris at $\mathrm{pH} 7.5,300 \mathrm{mM} \mathrm{NaCl}, 5 \mathrm{mM} \beta$-ME, and $1 \mathrm{mM}$ ethylenediaminetetraacetic acid (EDTA). Fractions containing Esa1 based on SDS-PAGE and activity assays were pooled and concentrated. The final concentration of Esa1 was determined by the method of Bradford (22). Aliquots were frozen by liquid nitrogen and stored at $-20{ }^{\circ} \mathrm{C}$.

To purify the picNuA4 complex, Esa1, Yng2, and Epl1 were coexpressed using the polycistronic expression system developed by Tan and co-workers (23). The recombinant complex is composed of His-tagged Epl1 (residues 51-380), Esa1, and Yng2 (residues 1-218), which has been shown to acetylate nucleosomes efficiently (21). The complex was expressed in BL21(DE3)pLysS. Cells were grown in $1 \mathrm{~L}$ of $2 \times \mathrm{YT}_{\text {To }} \mathrm{OD}_{600}=0.4-0.6$ and then induced with $0.4 \mathrm{mM}$ IPTG. Induction was performed at $37^{\circ} \mathrm{C}$ for $4 \mathrm{~h}$ before cells were harvested by centrifugation. Purification and storage of the complex were essentially the same as for Esa1, except all buffers contained $100 \mathrm{mM} \mathrm{NaCl}$.

\section{Histone Purification}

Recombinant Xenopus laevis core histones were purified according to the method developed by Luger and co-workers with modifications summarized below (plasmids were a generous gift of K. Luger, Colorado State University) (24). All urea buffers contained Tris at pH 8.0 instead of sodium acetate, and a $5 \mathrm{~mL}$ HiTrap Q column (Amersham Biosciences) was run inline before the SP column to further purify histones from DNA and bacterial proteins. Concentrations of the histone protein for use in enzyme assays were determined using published extinction coefficients and confirmed using the bicinchoninic acid (BCA) assay (Pierce Scientific). Globular histone $\mathrm{H} 4$ was purified following the method of full-length $\mathrm{H} 4$ purification.

\section{Peptide Synthesis}

Histone $\mathrm{H}_{1-7}$ (SGRGKGG), histone H4 $4_{1-20}$ (SGRGKGGKGLGKGGAKRHRK), and histone $\mathrm{H}_{1-20}$ (ARTKQTARKSTGGKAPRKQL) corresponding to residues in the Nterminal tail were synthesized by the Biotechnology Center at the University of WisconsinMadison. 


\section{Assembly of Nucleosome Core Particles (NCPs) and Nucleosome Arrays}

Histone octamer assembly and the formation of NCPs were performed in the method of Luger and co-workers (24). Nucleosome arrays were produced following the method of Carruthers and co-workers (25).

\section{Determination of $\mathrm{k}_{\mathrm{cat}} / \mathrm{K}_{\mathrm{m}}$ for Histone Substrates}

To determine the $k_{\text {cat }} / K_{\mathrm{m}}$ for substrates, either a radioactive filter-binding assay or pyruvate dehydrogenase enzyme coupled assay was performed at concentrations of the substrate ranging from 0.1 to $3000 \mu \mathrm{M}$, depending upon the substrate. Assays were performed as detailed by Berndsen and Denu, with conditions summarized below (26). All reactions were performed either in $1 \times$ TEA ( $50 \mathrm{mM}$ Tris, $50 \mathrm{mM}$ Bis-Tris, and $100 \mathrm{mM}$ sodium acetate) at $\mathrm{pH} 7.0$ or 50 $\mathrm{mM}$ Tris buffer at $\mathrm{pH} 7.5$ and $25^{\circ} \mathrm{C}$. All reactions contained $1 \mathrm{mM}$ DTT and 50-110 $\mu \mathrm{M}$ acetyl$\mathrm{CoA}\left(0.1-0.4 \mu \mathrm{Ci}\right.$ of ${ }^{3} \mathrm{H}$-acetyl-CoA in filter-binding assays). The concentration of Esa1 in assays was $0.4-1.6 \mu \mathrm{M}$, and the concentration was $0.01-0.3 \mu \mathrm{M}$ for picNuA4, depending upon the assay and substrate.

To determine the initial $k_{\mathrm{cat}} / K_{\mathrm{m}}$, saturation curves were performed. Data collected in saturation curve experiments were fit to the Michaelis-Menten equation (eq 1) using Kaleidagraph (Synergy Software, Reading, PA)

$$
v=\frac{\left(k_{\mathrm{cat}}[\mathrm{E}] t^{[\mathrm{S}]}\right)}{\left(K_{\mathrm{m}}+[\mathrm{S}]\right)}
$$

where $v$ is the velocity, $k_{\text {cat }}$ is the apparent first-order rate constant in $\mathrm{s}^{-1},[\mathrm{E}]_{t}$ is the concentration of the enzyme, [S] is the concentration of the substrate, and $K_{\mathrm{m}}$ is the concentration of the substrate at one-half $k_{\text {cat }}$.

An average $k_{\mathrm{cat}} / K_{\mathrm{m}}\left(k_{\mathrm{cat}} / K_{\mathrm{avg}}\right)$ of all possible acetylations in the assay was determined from data collected in progress curve experiments. Data collected from progress curve experiments were fit to an integrated form of the Michaelis-Menten equation (eq 2) using Kaleidagraph $(26,27)$

$$
t=\frac{\mathrm{p}}{\left(k_{\left.\mathrm{cat}^{[\mathrm{E}]} t\right)}\right)}+\left(\frac{K_{\mathrm{m}}}{\left(k_{\mathrm{cat}}{ }^{[\mathrm{E}]} t\right.}\right) \ln \left(\frac{\mathrm{p}^{\infty}}{\left(\mathrm{p}^{\infty}-\mathrm{p}\right)}\right)
$$

where $t$ is the time, $\mathrm{p}$ is the product formed at time $t, \mathrm{p}^{\infty}$ is the product formed at a time where the reaction has come to completion, and $[\mathrm{E}]_{t}$ is the total concentration of the enzyme.

Where possible, both $k_{\text {cat }} / K_{\text {avg }}$ and $k_{\text {cat }}$ were determined from the progress curve; however, for a few substrates, the $k_{\text {cat }}$ was set at $1.5 \mathrm{~s}^{-1}$, a turnover number experimentally determined for $\mathrm{H} 3$ histone, to allow for accurate determination of $k_{\mathrm{cat}} / K_{\mathrm{avg}}$. All values were corrected to units of (M histone $)^{-1} \mathrm{~s}^{-1}$ by multiplying the number of acetylations per substrate.

\section{C-Terminal Truncation of Histone $\mathrm{H} 4$}

To determine the portion of the $\mathrm{H} 4$ core domain critical for recognition, histone $\mathrm{H} 4$ was cleaved by either $\mathrm{CNBr}$, which cleaves at methionine, or Staphylococcal V8 Glu-C (Sigma), which cleaves predominantly at glutamate. CNBr cleavage was performed in $7 \mathrm{M}$ urea overnight in the dark with $10 \mathrm{mg}$ of $\mathrm{H} 4$ as described by Kaiser and Metzka (28). The histone fragment corresponding to residues $1-83$ was purified by dialysis for $18 \mathrm{~h}$ into $\mathrm{H}_{2} \mathrm{O}$ with $1 \mathrm{mM} \beta$-ME at $4{ }^{\circ} \mathrm{C}$ and then lyophilized. Glu-C cleavage of $\mathrm{H} 4$ was performed in $50 \mathrm{mM}$ Tris at $\mathrm{pH} 7.0$ for $6 \mathrm{~h}$ at $37^{\circ} \mathrm{C}$ with 3 units of Glu-C. The reaction was flash-frozen to stop cleavage. The cleavage product corresponding to residues $1-52$ was purified by size exclusion in $7 \mathrm{M}$ urea, 
$1000 \mathrm{mM} \mathrm{NaCl}, 20 \mathrm{mM}$ Tris at $\mathrm{pH}$ 8.0, $1 \mathrm{mM}$ EDTA, and $1 \mathrm{mM} \beta$-ME. Fractions containing the correct fragment as determined by SDS-PAGE were pooled, dialyzed, and lyophilized as with the $\mathrm{CNBr}$ reaction. Confirmation of the fragment size and the molecular weight was determined by matrix-assisted laser desorption ionization time-of-flight mass spectrometry (MALDI-TOF MS) on a Bruker Biflex III (Bruker Daltonics, Billerica, MA) in the Biotechnology Center at the University of Wisconsin. Filter-binding assays were then performed as described above with $30-50 \mathrm{nM}$ picNuA4 and $1-20 \mu \mathrm{M}$ of each peptide substrate.

\section{Competition of Core Domain Peptides of Histone H4 versus Histone H4}

To demonstrate the direct interaction of the $\mathrm{H} 4$ core domain with the picNuA4 complex, competition of the recombinant core domain was performed against histone H4. Using the filter-binding assay and conditions described above, the concentration of histone $\mathrm{H} 4$ varied from 0.5 to $26.4 \mu \mathrm{M}$ and the initial rate was determined at increasing levels of the $\mathrm{H} 4$ core domain. Rates were determined from where the acetylation reaction was linear with time. Data were fitted in Kinetasyst (Intellikinetics, State College, PA) to the equation for competitive inhibition to determine affinity (eq 3)

$$
v=\left|\frac{\left(k_{\mathrm{cat}^{[\mathrm{E}]}}{ }^{[\mathrm{S}])}\right.}{K_{\mathrm{m}}\left\{1+\frac{[\mathrm{I}]}{K_{\mathrm{i}}}\right\}+[\mathrm{S}]}\right|
$$

where [I] is the concentration of the inhibitor and $K_{\mathrm{i}}$ is the inhibition constant.

\section{RESULTS}

\section{Catalytic Efficiency Reveals Determinants of Substrate Recognition}

To explore the mechanism of nucleosomal acetylation by picNuA4, it was first necessary to determine what structural features within the nucleosome were required for efficient binding and catalysis. To assess the contribution from both substrate binding and acetylation, a steadystate kinetic approach was employed, utilizing the kinetic parameter $k_{\text {cat }} / K_{\mathrm{m}}$. The $k_{\mathrm{cat}} / K_{\mathrm{m}}$ is the pseudo-second-order rate constant that includes contributions from both binding and catalysis and is a direct measure of catalytic efficiency (29). To determine $k_{\mathrm{cat}} / K_{\mathrm{m}}$, previously described methods for measuring HAT activity from substrate saturation and progress curves were applied to this study of nucleosome recognition by Esa1 and picNuA4 (26). The $k_{\text {cat }} /$ $K_{\mathrm{m}}$ value determined from a saturation curve reflects the efficiency of the first acetylation (29). Figure 1A shows a representative histone $\mathrm{H} 4$ saturation curve for picNuA4, where the initial rate of acetylation is plotted as a function of the varied free histone $\mathrm{H} 4$ concentration. Acetylation of histone $\mathrm{H} 4$ by picNuA4 occurs at a $k_{\text {cat }}$ value of $2.6 \pm 0.3 \mathrm{~s}^{-1}$, having a $K_{\mathrm{m}}$ value of $1.9 \pm 0.2 \mu \mathrm{M}$ for $\mathrm{H} 4$ and a $k_{\text {cat }} / K_{\mathrm{m}}$ value of $1.4 \pm 0.3 \times 10^{6} \mathrm{M}^{-1} \mathrm{~s}^{-1}$.

Because Esa1 can acetylate different histones and the same tail multiple times, a previously developed assay was utilized to measure the overall efficiency of multiple acetylations (20, 26,27,30-32). In this assay, acetylation is monitored over time until all targeted lysine residues are acetylated. The resulting progress curves are then fitted to an integrated form of the Michaelis-Menten equation to obtain a $k_{\mathrm{cat}} / K_{\mathrm{m}}$ value, which reflects the average efficiency of acetylation across all sites and will be referred to as $k_{\text {cat }} / K_{\text {avg }}(26)$. In Figure $1 \mathrm{~B}$, a representative progress curve for picNuA4 acetylation of histone $\mathrm{H} 4$ is shown. From the integrated fit, a $k_{\text {cat }}$ of $1.7 \pm 0.3 \mathrm{~s}^{-1}$ and a $k_{\text {cat }} / K_{\text {avg }}$ of $1.9 \pm 0.3 \times 10^{6} \mathrm{M}^{-1} \mathrm{~s}^{-1}$ were obtained (Figure $1 \mathrm{~B}$ ), in good agreement with values determined from the saturation curve (Figure 1A). The average number of acetylations for $\mathrm{H} 4$ was calculated to be $3 \pm 1$ from six separate experiments. Consistent with the number of acetylation sites determined from the above filter-binding HAT assays, triton-acetic acid-urea gel electrophoresis (TAU gel) analysis confirmed four 
acetylations (Supplementary Figure 1 in the Supporting Information), and MS analysis identified lysine 5, 8, 12, and 16 as the acetylation sites (Lee, S., and Denu, J. M., unpublished data). All kinetic parameters determined from saturation and progress curves were normalized to units of (M histone $)^{-1} \mathrm{~s}^{-1}$ using the number of acetylation sites per histone determined from TAU gel analysis.

\section{Substrate Specificity and Nucleosome Recognition by the picNuA4 Complex}

Having established the ability to compare the acetylation efficiency of different substrates, we next determined the $k_{\text {cat }} / K_{\mathrm{m}}$ and $k_{\text {cat }} / K_{\text {avg }}$ for each substrate, starting with the simplest histone peptide substrates and building to nucleosome arrays. We first examined peptide substrates of varying length, derived from the $\mathrm{N}$-terminal tails of histones $\mathrm{H} 3$ and $\mathrm{H} 4$. The $k_{\mathrm{cat}} / K_{\mathrm{m}}$ values determined from saturation curves for two $\mathrm{H} 4$ peptides ( $\mathrm{H}_{1-7}$, SGRGKGG, and $\mathrm{H}_{1-20}$, SGRGKGGKGLGKGGAKRHRK) were $506 \pm 40$ and $545 \pm 87 \mathrm{M}^{-1} \mathrm{~s}^{-1}$, respectively, with $k_{\text {cat }}$ values of $0.5 \mathrm{~s}^{-1}$ (Figure 2). Using a similar analysis with a peptide corresponding to the $20 \mathrm{~N}$-terminal residues of $\mathrm{H} 3$ histone (H3 ${ }_{1-20}$, ARTKQTARKSTGGKAPRKQL), we determined a $k_{\text {cat }} / K_{\mathrm{m}}$ of $530 \pm 21 \mathrm{M}^{-1} \mathrm{~s}^{-1}$, nearly identical to that for the $\mathrm{H} 4$ peptides.

To assess the catalytic efficiency on free core histones, the $k_{\text {cat }} / K_{\mathrm{m}}$ values were measured for each of the core histones individually. The data summarized in Figure 2 show that histone H4 is the best substrate, with a $k_{\text {cat }} / K_{\mathrm{m}}$ of $1.4 \pm 0.3 \times 10^{6} \mathrm{M}^{-1} \mathrm{~s}^{-1}$, which is 3-35-fold higher than those observed for histones $\mathrm{H} 3, \mathrm{H} 2 \mathrm{~A}$, and $\mathrm{H} 2 \mathrm{~B}$. The marked preference for histones over histone peptides (100-2300-fold) suggests that contacts within the HFD are necessary for efficient acetylation and may participate in nucleosome recognition. The $k_{\mathrm{cat}} / K_{\mathrm{m}}$ and $k_{\mathrm{cat}} t$ $K_{\text {avg }}$ values for each of the core histones were in good agreement, indicating that the first and average acetylation efficiencies are similar.

The acetylation efficiency was next determined using NCPs as a substrate. NCPs were rapidly acetylated by picNuA4, yielding an initial $k_{\text {cat }} / K_{\mathrm{m}}$ value of $2.2 \pm 0.3 \times 10^{7} \mathrm{M}^{-1} \mathrm{~s}^{-1}$, a nearly 20 -fold increase over the value with free histone H4 (Figure 2). Because of the low $K_{\mathrm{m}}$ for NCPs $(<190 \mathrm{nM})$, accurate data below the $K_{\mathrm{m}}$ was difficult to obtain in saturation curves and, therefore, this rate is a lower limit for the actual $k_{\text {cat }} / K_{\mathrm{m}}$ value. Not surprisingly, the $k_{\text {cat }} / K_{\text {avg }}$ value for NCPs was $\sim 5$-fold lower than the $k_{\text {cat }} / K_{\mathrm{m}}$ value obtained from the saturation curve (Figure 2). This small 5-fold difference results from the slower rates of acetylation on $\mathrm{H} 3$ and $\mathrm{H} 2 \mathrm{~A}$, which are included in the $k_{\text {cat }} / K_{\text {avg }}$ value for the nucleosome.

Because chromatin is a polymer of individual nucleosomes, this super-structure may influence the ability of HAT complexes to bind, recognize, and acetylate histones. Here, we utilized a nucleosome array as the substrate and determined the catalytic efficiencies from the methods described above. This array consists of 12 histone octamers on a single, linear fragment of DNA and has been used extensively to model the chromatin structure in vitro (33). The $k_{\text {cat }} t$ $K_{\text {avg }}$ value obtained for nucleosome arrays was $8.0 \pm 0.8 \times 10^{6} \mathrm{M}^{-1} \mathrm{~s}^{-1}$, which is similar to the $k_{\text {cat }} / K_{\text {avg }}\left(4.6 \pm 2.3 \times 10^{6} \mathrm{M}^{-1} \mathrm{~s}^{-1}\right)$ value determined for NCPs (Figure 2). It is important to point out that, under the salt conditions of our assays, the tails in the arrays are not expected to be engaged in compaction and are loosely interacting with nucleosomal DNA (33-35). The observation that nucleosomal arrays and NCPs were acetylated by picNuA4 with nearly identical efficiency is consistent with this scenario and suggests that the fundamental unit recognized by picNuA4 is the nucleosome.

\section{picNuA4 Efficiently Tetra-acetylates Histone H4}

The number of acetylations that picNuA4 can catalyze per histone has not been fully established. To determine the number of acetylations by picNuA4 on $\mathrm{H} 4$, we then used a TAU gel, which can separate histones based on modification state and size (36) (see the Supporting 
Information). The TAU gel unequivocally shows that $\mathrm{H} 4$ is acetylated 4 times, as shown previously for Esa1 (Supplementary Figure 1 in the Supporting Information) (30). Interestingly, the rates of formation of each acetyl-H4 form are similar, consistent with our kinetic finding that the efficiency of the initial acetylation of $\mathrm{H} 4$ and the average acetylation are similar (data not shown and Figure 2). To determine the extent of acetylation between histones, we monitored the acetylation of free histones compared to nucleosomal histones. Using picNuA4, radio-labeled acetyl-CoA, and either an equimolar mix of free histones or nucleosome arrays, the reaction was allowed to run to completion with time points taken between 0 and $3600 \mathrm{~s}$. Samples were then run on SDS-PAGE and analyzed by phosphorimaging. The ratio of the density determined using Imagequant with both reactions at completion of the free histones and the nucleosome was determined to be 4:1:1 H4/ H2A/ H3 (Supplementary Figure 1 in the Supporting Information). H2B was not significantly acetylated during the time course of the experiment.

\section{Epl1 and Yng2 Stabilize Esa1}

Several papers have suggested that Esa1 lacked measurable nucleosome acetylation activity, implying that the subunits Ep11 and Yng2 may be required for activity on nucleosomal substrates $(14,30,31)$. To examine the role of Epl1 and Yng2, we determined the catalytic efficiencies of the catalytic subunit Esa 1 for $\mathrm{H}_{4}{ }_{1-20}$, histone $\mathrm{H} 4$, and nucleosome arrays and then compared the preference for these substrates to that of picNuA4. The apparent turnover $\left(k_{\text {cat }}\right)$ for Esa1 was 2-3 orders of magnitude lower than that observed with picNuA4 against all substrates examined. However, Esa1 exhibited similar $K_{\mathrm{m}}$ values to those observed with picNuA4 for free $\mathrm{H} 4$ and $\mathrm{H} 4$ peptides; i.e., the $K_{\mathrm{m}}(1.4 \mathrm{mM})$ for Esa1 with $\mathrm{H} 4{ }_{1-20} \sim$ the $K_{\mathrm{m}}$ $(1.0 \mathrm{mM})$ for picNuA4 on $\mathrm{H}_{1-20}$, and the $K_{\mathrm{m}}(1.1 \mu \mathrm{M})$ for Esa1 with $\mathrm{H} 4 \sim$ the $K_{\mathrm{m}}(2.1 \mu \mathrm{M})$ for picNuA4 on H4 (Supplementary Figure 2 in the Supporting Information). This behavior can be observed when an enzyme preparation is unstable and inactive, but a small fraction of the enzyme is capable of native-type binding and catalysis. Although the molecular basis for the low catalytic rates is unclear at this point, the catalytic efficiencies of Esa1 toward various substrates could be compared and the ability of Esa1 to discriminate among histone substrates was assessed. With Esa1, the $k_{\text {cat }} / K_{\mathrm{m}}$ value for $\mathrm{H} 4_{1-20}$ compared to that for $\mathrm{H} 4$ or nucleosome arrays was 2000-fold lower, suggesting that, similar to picNuA4, Esa1 requires the HFD of H4 for efficient acetylation (Figure 3). However, unlike picNuA4, Esa1 acetylates nucleosomes with rates comparable to that for free histone H4 (Figure 3). The latter result suggests that Epl1 and Yng2 may provide additional interaction surfaces that bind and recognize nucleosomal substrates, as proposed previously $(10,14,15,21,37)$. The importance of Ep11 and Yng2 is underscored by the 3500 -fold difference in $k_{\text {cat }} / K_{\mathrm{m}}$ values between Esa1 and picNuA4 on nucleosomal substrates (Figures 2 and 3 ).

\section{Histone Tails Function Independently}

To examine whether the histone tails contribute to the binding and acetylation of $\mathrm{H} 4$ within the nucleosome, we compared the $k_{\mathrm{cat}} / K_{\mathrm{avg}}$ values of nucleosome arrays missing one or more of the histone tails. Separate removal of the H3, H2A, or H2B tails did not significantly affect the average rate of array acetylation by the picNuA4 complex (Table 1). In contrast to deletion of the $\mathrm{H} 3, \mathrm{H} 2 \mathrm{~A}$, or $\mathrm{H} 2 \mathrm{~B}$ tails, the loss of the $\mathrm{H} 4$ tail reduced $k_{\text {cat }} / K_{\text {avg }}$ by 80 -fold, yielding a $k_{\text {cat }} / K_{\text {avg }}$ value of $1.0 \pm 0.2 \times 10^{5} \mathrm{M}^{-1} \mathrm{~s}^{-1}$. Background levels of acetylation by picNuA4 are observed on nucleosome arrays missing all four histone tails (Table 1). These data are consistent with the HFD playing an essential role in efficient tail acetylation. To determine if picNuA4 could bind to nucleosomes missing the histone tails, we performed gel-filtration chromatography and compared the binding of picNuA4 to nucleosomes and to the nucleosome lacking all four histone tails. The elution profiles shown in Figure 4 indicate that picNuA4 coelutes with nucleosomes whether or not the tails are present, suggesting that nontail interactions can mediate efficient nucleosomal binding. Consistent with tight binding through 
nontail interactions, an $\mathrm{H} 4$ construct containing residues 20-102 was an excellent competitive inhibitor against full-length $\mathrm{H} 4$, with a $K \mathrm{i}(1.5 \pm 0.6 \mu \mathrm{M})$ similar to the $K_{\mathrm{m}}$ for $\mathrm{H} 4(1.9 \mu \mathrm{M})$

(Supplementary Figure 3 in the Supporting Information and Figure 1).

\section{picNuA4 Requires Histone H4 Residues 21-52 for Efficient Catalysis}

To determine which regions of the H4 HFD were involved in the high catalytic efficiency of histone $\mathrm{H} 4$ acetylation, we generated $\mathrm{C}$-terminal truncations of $\mathrm{H} 4$ and determined the steadystate kinetic parameters, comparing these values to those of full-length $\mathrm{H} 4\left(\mathrm{H}_{1}{ }_{1-102}\right)$. Separately, using CNBr and Glu-C from Staphylococcus aureus, the H4 core domain was cleaved at methionine and glutamate residues, respectively, to eliminate residues 84-102 and 53-102 (Figure 5A) (38). Peptides were purified by size-exclusion chromatography (Figure 5B). The histone fragment truncated by Glu-C was shown by MALDI-TOF MS to correspond to residues $1-52$ of histone $\mathrm{H} 4$ (data not shown). Using the truncated histone $\mathrm{H}_{4}{ }_{1-52}$ as the substrate, the resulting saturation curve yielded a $k_{\text {cat }} / K_{\mathrm{m}}$ value of $4.6 \pm 0.4 \times 10^{5} \mathrm{M}^{-1} \mathrm{~s}^{-1}$ (Figure 5C). This value is approximately 3 -fold less that the value determined for $\mathrm{H}_{1-102}(1.3$ $\pm 0.2 \times 10^{6} \mathrm{M}^{-1} \mathrm{~s}^{-1}$ ) but still nearly 800 -fold greater than $\mathrm{H}_{4-20}$. The $\mathrm{H}_{1-84}$ peptide yielded similar rates to that of $\mathrm{H}_{1-102}$ and $\mathrm{H}_{1-52}$ (data not shown). These results indicate that histone $\mathrm{H} 4$ residues $21-52$ are necessary for the observed high catalytic efficiency toward $\mathrm{H}_{1-102}$ by picNuA4.

\section{DISCUSSION}

Previous mechanistic studies of HAT enzymes have focused mainly on how the catalytic subunits act on histone tail peptides $(11,17,18,39,40-44)$. Although such investigations have led to important insights into how HAT catalytic subunits can bind and acetylate isolated histone tails, few investigations have evaluated the functional determinants required for acetylation of the physiological substrate, the nucleosome. Here, using kinetic and biochemical approaches, we compared histone-based substrates of increasing complexity to determine the critical components of nucleosome recognition by the picNuA4 complex. We find that the HFD of $\mathrm{H} 4$ is the major nucleosomal interaction site for picNuA4, providing new mechanistic insight into the remarkable efficiency and site selection of histone acetylation.

A comparison of the catalytic efficiencies of Esa1 and picNuA4 revealed that the complex is 100-1000-fold more efficient than Esa1 against all substrates examined, with the largest difference observed on nucleosomal substrates. When tail peptides and free histones were analyzed, the similarity in the $K_{\mathrm{m}}$ values between Esa1 and picNuA4 supports a stabilizing role for Epl1 and Yng2. Furthermore, Epl1 and Yng2 may provide additional contacts with nucleosomal substrates that lead to enhanced binding and/or catalysis. In support of this, picNuA4 is 20 times more efficient on NCPs than it is on histone H4, while Esa1 possesses similar activity on histone $\mathrm{H} 4$ and nucleosome array substrates. The latter role for Epl1 and Yng2 is consistent with observations that the conserved enhancer of the polycomb homology region $[\mathrm{E}(\mathrm{Pc}) \mathrm{A}]$ of Epl1 and a region near the $\mathrm{N}$ terminus of $\mathrm{Yng} 2$ are critical for nucleosomal acetylation by picNuA4 $(14,21)$. Moreover, the fact that picNuA4 possesses a $k_{\text {cat }} / K_{\mathrm{m}}$ value of $>2.2 \times 10^{7} \mathrm{M}^{-1} \mathrm{~s}^{-1}$ on NCPs, a value approaching the limit imposed by diffusion, emphasizes the importance of studying HATs within their relevant complexes (29).

Although studies of histone modifications have focused on histone tails, we find that the nontail regions play important roles for picNuA4 function. Individual histones are 300-2500-fold better substrates of picNuA4 than the corresponding histone tails, suggesting that picNuA4 recognizes and binds the HFD of core histones in addition to the tail. This is supported by interaction and inhibition studies, indicating that picNuA4 can bind with high affinity to tailless nucleosomes and residues 20-102 of H4 (Figure 4 and Supplementary Figure 3 in the Supporting Information). Among histone proteins, one common feature to the HFD regions is 
the propensity to form $\alpha$ helices near the tail, which may serve as a stable recognition site for picNuA4 (38). Using a variety of truncated histone H4 constructs, we identified residues 2152 to be critical for $\mathrm{H} 4$ acetylation. Nucleosome crystal structure data shows that this stretch contains at least one $\alpha$ helix (38). In determining the helical content of several $\mathrm{H} 4$ peptides and truncations, we find a correlation between a $\alpha$-helical content and the efficiency of acetylation, supporting the proposal that Esa1 and picNuA4 bind to helical regions within the HFD of histones (Berndsen, C. E., and Denu, J. M., unpublished data).

Recognition of the HFD appears to be an intrinsic function of Esa1, because both picNuA4 and Esa1 prefer full-length histones to tail peptides by 2-3 orders of magnitude (Figures 2 and 3 ). In support of histone recognition by the HAT catalytic subunit, Akhtar and Becker demonstrated that the related MYST family member, MOF, bound nucleosomes lacking histone tails (2). Interestingly, this interaction was ablated upon mutation of the Zn-finger domain of MOF. Similarly, the Zn-finger domain of Sas3 and Tip60 were shown to be critical for substrate acetylation activity (45-47). Using the Y56A chromodomain mutant of Esa1, we found no significant effect on the acetylation rate of histones $\mathrm{H} 3$ and $\mathrm{H} 4$, suggesting that the chromodomain is not crucial for binding the HFD (Arnold, K., and Denu, J. M., unpublished data) (21). Collectively, these data support our finding that the recognition of HFD is an inherent property of Esa1, possibly mediated by the Zn-finger-like domain. This general mechanism of substrate binding may be conserved among the MYST family of HATs.

We propose that picNuA4 interacts with nucleosomes on the open face of the histone octamer, mediated at least in part by residues 21-52 of H4 (Figure 6). There are two consequences of this binding mechanism. First, primary interactions with the HFD of $\mathrm{H} 4$ serve to restrict substrate access to only lysines within the tails of $\mathrm{H} 4$ and $\mathrm{H} 2 \mathrm{~A}$, which protrude from the same face of the nucleosome (Figure 6). Interestingly, in the H4 tail-less nucleosome array, the acetylation rate of remaining tails was decreased $\sim 80$-fold, suggesting that the $\mathrm{H} 4$ tail may be required for $\mathrm{H} 2 \mathrm{~A}$ acetylation in the context of the nucleosome (Table 1). Although an intriguing possibility, it is not clear whether $\mathrm{H} 4$ tail acetylation must precede efficient acetylation of $\mathrm{H} 2 \mathrm{~A}$. Consistent with the preference of picNuA4 for acetylating tails on the open face of the nucleosome, free and nucleosomal $\mathrm{H} 4$ and $\mathrm{H} 2 \mathrm{~A}$ were acetylated rapidly, while the rate of $\mathrm{H} 3$ acetylation was significantly reduced in the nucleosome compared to free H3 (Supplementary Figure 1 in the Supporting Information). The nucleosome structure reveals that the DNA would prevent picNuA4 from interacting with both the $\mathrm{H} 3$ tail and $\mathrm{H} 3 \mathrm{HFD}$, limiting $\mathrm{H} 3$ tail acetylation (38). Second, interactions with the H4 HFD allow the enzyme to be "tethered" to the histone/nucleosome, thereby increasing the effective concentration of the histone tail. Tethering would permit the enzyme to efficiently catalyze successive cycles (4 rounds) of $\mathrm{H} 4$ tail acetylation, an inherent feature of picNuA4 (Figure 2 and Supplementary Figure 1 in the Supporting Information).

The results presented in this study define key features of the nucleosome that are recognized by the picNuA4 HAT complex. Surprisingly, we find that histone tails are dispensable for nucleosome binding and do not influence the ability with which the $\mathrm{H} 4$ tail is acetylated. Instead, we discovered that the HFD regions of histones are critical for tight binding and efficient tail acetylation. This study is the first to utilize a detailed biochemical and kinetic analysis to functionally probe nucleosome recognition by a HAT complex. The presented evidence suggests that chromatin-modifying complexes may have evolved to recognize the HFD features present on the surface of the nucleosome.

\section{Supplementary Material}

Refer to Web version on PubMed Central for supplementary material. 


\section{Acknowledgements}

We thank Karolin Luger for the histone expression plasmids. We also thank Amy Andrew and members of the Denu lab for helpful comments and discussions on this manuscript, especially Brian Smith, Kevin Arnold, Casey Hallows, and Suzi Lee. We also thank Silvia Cavagnero for helpful discussions on the structural data on the histones and Darrell McCaslin for technical assistance and guidance in collection of CD spectra.

\section{References}

1. Carrozza MJ, Utley RT, Workman JL, Cote J. The diverse functions of histone acetyltransferase complexes. Trends Genet 2003;19:321-329. [PubMed: 12801725]

2. Akhtar A, Becker PB. The histone $\mathrm{H} 4$ acetyltransferase MOF uses a $\mathrm{C} 2 \mathrm{HC}$ zinc finger for substrate recognition. EMBO Rep 2001;2:113-118. [PubMed: 11258702]

3. Luger K, Hansen JC. Nucleosome and chromatin fiber dynamics. Curr Opin Struct Biol 2005;15:188196. [PubMed: 15837178]

4. Marmorstein R, Roth SY. Histone acetyltransferases: Function, structure, and catalysis. Curr Opin Genet Dev 2001;11:155-161. [PubMed: 11250138]

5. Bickmore WA, van der Maarel SM. Perturbations of chromatin structure in human genetic disease: Recent advances. Hum Mol Genet 2003;12:R207-R213. [PubMed: 12915455]

6. Tse C, Sera T, Wolffe AP, Hansen JC. Disruption of higher-order folding by core histone acetylation dramatically enhances transcription of nucleosomal arrays by RNA polymerase m. Mol Cell Biol 1998;18:4629-4638. [PubMed: 9671473]

7. Allfrey VG, Faulkner R, Mirsky AE. Acetylation and methylation of histones and their possible role in the regulation of RNA synthesis. Proc Natl Acad Sci USA 1964;51:786-794. [PubMed: 14172992]

8. de la Cruz X, Lois S, Sanchez-Molina S, Martinez-Balbas MA. Do protein motifs read the histone code? Bioessays 2005;27:164-175. [PubMed: 15666348]

9. Roth SY, Denu JM, Alls CD. Histone acetyltransferases. Annu Rev Biochem 2001;70:81-120. [PubMed: 11395403]

10. Doyon Y, Cote J. The highly conserved and multifunctional NuA4 HAT complex. Curr Opin Genet Dev 2004;14:147-154. [PubMed: 15196461]

11. Poux AN, Marmorstein R. Molecular basis for Gcn5/PCAF histone acetyltransferase selectivity for histone and non-histone substrates. Biochemistry 2003;42:14366-14374. [PubMed: 14661947]

12. Bird AW, Yu DY, Pray-Grant MG, Qiu Q, Harmon KE, Megee PC, Grant PA, Smith MM, Christman MF. Acetylation of histone H4 by Esa1 is required for DNA double-strand break repair. Nature 2002;419:411-415. [PubMed: 12353039]

13. Reid JL, Iyer VR, Brown PO, Struhl K. Coordinate regulation of yeast ribosomal protein genes is associated with targeted recruitment of Esa1 histone acetylase. Mol Cell 2000;6:1297-1307. [PubMed: 11163204]

14. Boudreault AA, Cronier D, Selleck W, Lacoste N, Utley RT, Allard S, Savard I, Lane WS, Tan S, Cote J. Yeast enhancer of poly comb defines global Esa1-dependent acetylation of chromatin. Genes Dev 2003;17:1415-1428. [PubMed: 12782659]

15. Doyon Y, Selleck W, Lane WS, Tan S, Cote J. Structural and functional conservation of the NuA4 histone acetyltransferase complex from yeast to humans. Mol Cell Biol 2004;24:1884-1896. [PubMed: 14966270]

16. Durant M, Pugh BF. Genome-wide relationships between TAF1 and histone acetyltransferases in Saccharomyces cerevisiae. Mol Cell Biol 2006;26:2791-2802. [PubMed: 16537921]

17. Clements A, Poux AN, Lo WS, Pillus L, Berger SL, Marmorstein R. Structural basis for histone and phosphohistone binding by the GCN5 histone acetyltransferase. Mol Cell 2003;12:461-473. [PubMed: 14536085]

18. Rojas JR, Trievel RC, Zhou J, Mo Y, Li X, Berger SL, Allis CD, Marmorstein R. Structure of tetrahymena GCN5 bound to coenzyme A and a histone H3 peptide. Nature 1999;401:93-98. [PubMed: 10485713]

19. Strahl BD, Allis CD. The language of covalent histone modifications. Nature 2000;403:41-45. [PubMed: 10638745] 
20. Utley RT, Lacoste N, Jobin-Robitaille O, Allard S, Cote J. Regulation of NuA4 histone acetyltransferase activity in transcription and DNA repair by phosphorylation of histone $\mathrm{H} 4$. Mol Cell Biol 2005;25:8179-8190. [PubMed: 16135807]

21. Selleck W, Fortin I, Sermwittayawong D, Cote J, Tan S. The Saccharomyces cerevisiae Piccolo NuA4 histone acetyltransferase complex requires the enhancer of polycomb A domain and chromodomain to acetylate nucleosomes. Mol Cell Biol 2005;25:5535-5542. [PubMed: 15964809]

22. Bradford MM. A rapid and sensitive method for the quantitation of microgram quantities of protein utilizing the principle of protein-dye binding. Anal Biochem 1976;72:248-254. [PubMed: 942051]

23. Tan S, Kern RC, Selleck W. The pST44 polycistronic expression system for producing protein complexes in Escherichia coli. Protein Expression Purif 2005;40:385-395.

24. Luger K, Rechsteiner TJ, Richmond TJ. Expression and purification of recombinant histones and nucleosome reconstitution. Methods Mol Biol 1999;119:1-16. [PubMed: 10804500]

25. Carruthers LM, Tse C, Walker KP III, Hansen JC. Assembly of defined nucleosomal and chromatin arrays from pure components. Methods Enzymol 1999;304:19-35. [PubMed: 10372353]

26. Berndsen CE, Denu JM. Assays for mechanistic investigations of protein/histone acetyltransferases. Methods 2005;36:321-331. [PubMed: 16085424]

27. Orsi BA, Tipton KF. Kinetic analysis of progress curves. Methods Enzymol 1979;63:159-183. [PubMed: 502859]

28. Kaiser R, Metzka L. Enhancement of cyanogen bromide cleavage yields for methionyl-serine and methionyl-threonine peptide bonds. Anal Biochem 1999;266:1-8. [PubMed: 9887207]

29. Fersht, A. Structure and Mechanism in Protein Science: A Guide to Enzyme Catalysis and Protein Folding. W. H. Freeman; New York: 1999.

30. Smith ER, Eisen A, Gu W, Sattah M, Pannuti A, Zhou J, Cook RG, Lucchesi JC, Allis CD. ESA1 is a histone acetyltransferase that is essential for growth in yeast. Proc Natl Acad Sci USA 1998;95:3561-3565. [PubMed: 9520405]

31. Clarke AS, Lowell JE, Jacobson SJ, Pillus L. Esa1p is an essential histone acetyltransferase required for cell cycle progression. Mol Cell Biol 1999;19:2515-2526. [PubMed: 10082517]

32. Allard S, Utley RT, Savard J, Clarke A, Grant P, Brandl CJ, Pillus L, Workman JL, Cote J. NuA4, an essential transcription adaptor/histone $\mathrm{H} 4$ acetyltransferase complex containing Esa1p and the ATM-related cofactor Tralp. EMBO J 1999;18:5108-5119. [PubMed: 10487762]

33. Hansen JC, Tse C, Wolffe AP. Structure and function of the core histone N-termini: More than meets the eye. Biochemistry 1998;37:17637-17641. [PubMed: 9922128]

34. Gordon F, Luger K, Hansen JC. The core histone N-terminal tail domains function independently and additively during salt-dependent oligomerization of nucleosomal arrays. J Biol Chem 2005;280:33701-33706. [PubMed: 16033758]

35. Hansen JC, Lohr D. Assembly and structural properties of subsaturated chromatin arrays. J Biol Chem 1993;268:5840-5848. [PubMed: 8449950]

36. Lennox RW, Cohen LH. Analysis of histone subtypes and their modified forms by polyacrylamide gel electrophoresis. Methods Enzymol 1989;170:532-549. [PubMed: 2770549]

37. Nourani A, Doyon Y, Utley RT, Allard S, Lane WS, Cote J. Role of an ING1 growth regulator in transcriptional activation and targeted histone acetylation by the NuA4 complex. Mol Cell Biol 2001;21:7629-7640. [PubMed: 11604499]

38. Luger K, Mader AW, Richmond RK, Sargent DF, Richmond TJ. Crystal structure of the nucleosome core particle at $2.8 \AA$ A resolution. Nature 1997;389:251-260. [PubMed: 9305837]

39. Hudson BP, Martinez-Yamout MA, Dyson HJ, Wright PE. Solution structure and acetyl-lysine binding activity of the GCN5 bromodomain. J Mol Biol 2000;304:355-370. [PubMed: 11090279]

40. Yan Y, Barlev NA, Haley RH, Berger SL, Marmorstein R. Crystal structure of yeast Esa1 suggests a unified mechanism for catalysis and substrate binding by histone acetyltransferases. Mol Cell 2000;6:1195-1205. [PubMed: 11106757]

41. Yan Y, Harper S, Speicher DW, Marmorstein R. The catalytic mechanism of the ESA1 histone acetyltransferase involves a self-acetylated intermediate. Nat Struct Biol 2002;9:862-869. [PubMed: 12368900] 
42. Tanner KG, Trievel RC, Kuo MH, Howard RM, Berger SL, Allis CD, Marmorstein R, Denu JM. Catalytic mechanism and function of invariant glutamic acid 173 from the histone acetyltransferase GCN5 transcriptional coactivator. J Biol Chem 1999;274:18157-18160. [PubMed: 10373413]

43. Tanner KG, Langer MR, Kim Y, Denu JM. Kinetic mechanism of the histone acetyltransferase GCN5 from yeast. J Biol Chem 2000;275:22048-22055. [PubMed: 10811654]

44. Thompson PR, Kurooka H, Nakatani Y, Cole PA. Transcriptional coactivator protein p300. Kinetic characterization of its histone acetyltransferase activity. J Biol Chem 2001;276:33721-33729. [PubMed: 11445580]

45. Takechi S, Nakayama T. Sas 3 is a histone acetyltransferase and requires a zinc finger motif. Biochem Biophys Res Commun 1999;266:405-410. [PubMed: 10600516]

46. Barren MR, Belaguli NS, Zhang SX, Trinh M, Iyer D, Merlo X, Lough JW, Parmacek MS, Bruneau BG, Schwartz RJ. Serum response factor, an enriched cardiac mesoderm obligatory factor, is a downstream gene target for Tbx genes. J Biol Chem 2005;280:11816-11828. [PubMed: 15591049]

47. Xiao H, Chung J, Kao HY, Yang YC. Tip60 is a co-repressor for STAT3. J Biol Chem 2003;278:11197-11204. [PubMed: 12551922]

48. DeLano, WL. DeLano Scientific LLC. South San Francisco, CA: 2005.

\section{Abbreviations}

HAT

histone acetyltransferase

HFD

histone-fold domain

GNAT

Gcn5-related acetyltransferase

MYST

MOZ, Ybf2/Sas3, Sas2, Tip60

$\operatorname{picNuA4}$

Piccolo NuA4 histone acetyltransferase complex

MALDI-TOF MS

matrix-assisted laser desorption ionization time-of-flight mass spectrometry

DTT

dithiothreitol

SDS-PAGE

sodium dodecyl sulfate-polyacrylamide gel electrophoresis

TAU gel

triton-acetic acid-urea gel electrophoresis

NCP

nucleosome core particle 

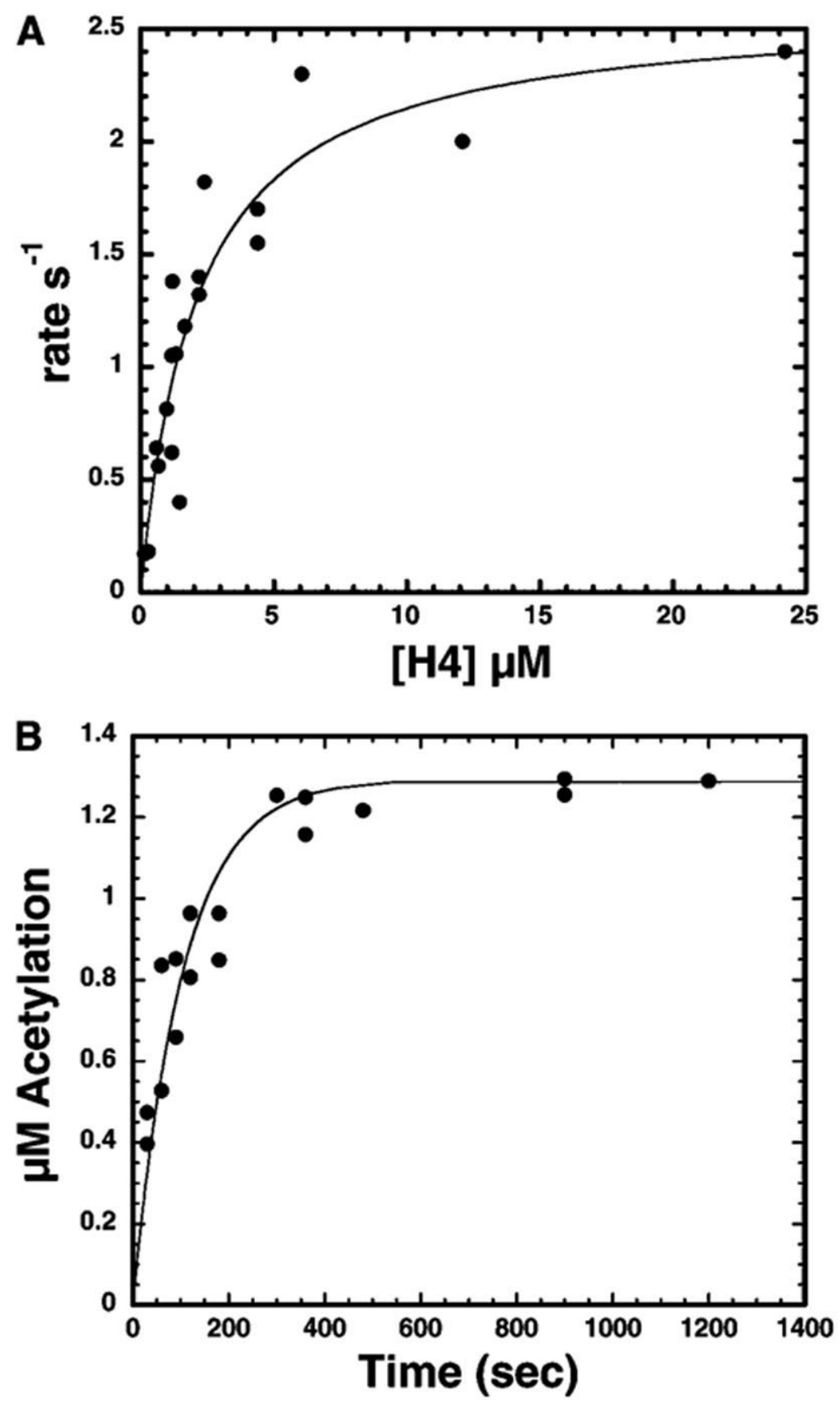

Figure 1.

(A) H4 saturation curve for the picNuA4 complex. The purified recombinant $\mathrm{H} 4$ histone varied from 0.15 to $24.4 \mu \mathrm{M}$ in $1 \times$ TBA at pH 7.0 with $1 \mathrm{mM}$ DTT, $100 \mu \mathrm{M}$ acetyl-CoA, and 0.011 $\mu \mathrm{M}$ picNuA 4 at $25^{\circ} \mathrm{C}$. Data were fitted to the Michaelis-Menten equation using Kaleidagraph to determine kinetic constants. The $k_{\text {cat }} / K_{\mathrm{m}}$ value was $1.4 \pm 0.2 \times 10^{6} \mathrm{M}^{-1} \mathrm{~s}^{-1}$; the $k_{\text {cat }}$ value was $2.6 \pm 0.3 \mathrm{~s}^{-1}$; and the $K_{\mathrm{m}}$ value was $1.9 \pm 0.2 \mu \mathrm{M}$. The saturation plot was performed in triplicate to ensure accuracy. (B) Progress curve for $\mathrm{H} 4$ acetylation by picNuA4. The acetylation of $\mathrm{H} 4$ by picNuA4 was monitored from 0 to $1200 \mathrm{~s}$ using the filter-binding assay. Reactions were performed in $1 \times$ TBA buffer with $1 \mathrm{mM}$ DTT, $0.5 \mu \mathrm{M}$. H4, $100 \mu \mathrm{M}$ acetyl$\mathrm{CoA}$, and $0.016 \mu \mathrm{M}$ picNuA4. To determine kinetic constants, data were fitted to an integrated 
form of the Michaelis-Menten equation in Kaleidagraph. The $k_{\text {cat }}$ value was $1.7 \pm 0.3 \mathrm{~s}^{-1}$, and the $k_{\text {cat }} / K_{\mathrm{m}}$ value was $1.9 \pm 0.3 \times 10^{6} \mathrm{M}^{-1} \mathrm{~s}^{-1}$, after being normalized for four acetylations per $\mathrm{H} 4$ as determined from TAU gel analysis. The progress curve was performed in triplicate to ensure accuracy. 


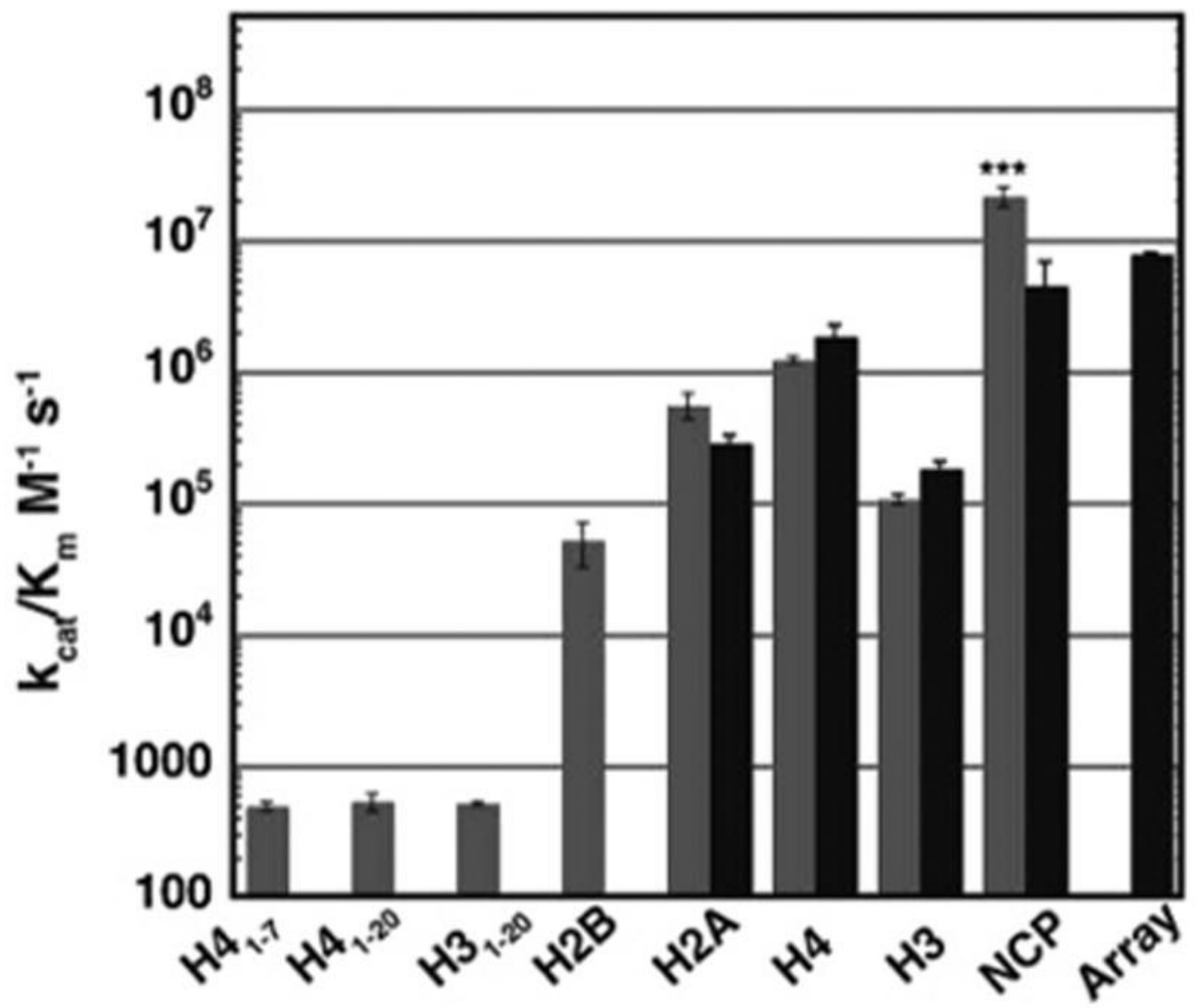

Figure 2.

Substrate specificity of picNuA4. All reactions contained $1 \times$ TBA at pH 7.0 or $50 \mathrm{mM}$ Tris at $\mathrm{pH} 7.2,1 \mathrm{mM}$ DTT, 50-100 $\mu \mathrm{M}$ acetyl-CoA, and 0.01-0.1 $\mu \mathrm{M}$ picNuA4 complex.

Concentrations of peptide substrates used in saturation curves were varied over a 10-fold range covering concentrations above and below the $K_{\mathrm{m}}$. Data were fitted to appropriate equations in Kaleidagraph to determine the kinetic constants. Each value is an average of three to six separate assays, with the standard deviation shown. Gray bars represent values from saturation curves $\left(k_{\mathrm{cat}} / K_{\mathrm{m}}\right)$, and black bars represent values determined from progress curves $\left(k_{\mathrm{cat}} /\right.$ $K_{\text {avg }}$. (***) Value represents the lower limit for initial $k_{\text {cat }} / K_{\mathrm{m}}$ of NCPs because data below $150 \mathrm{nM}$ were not collected. 


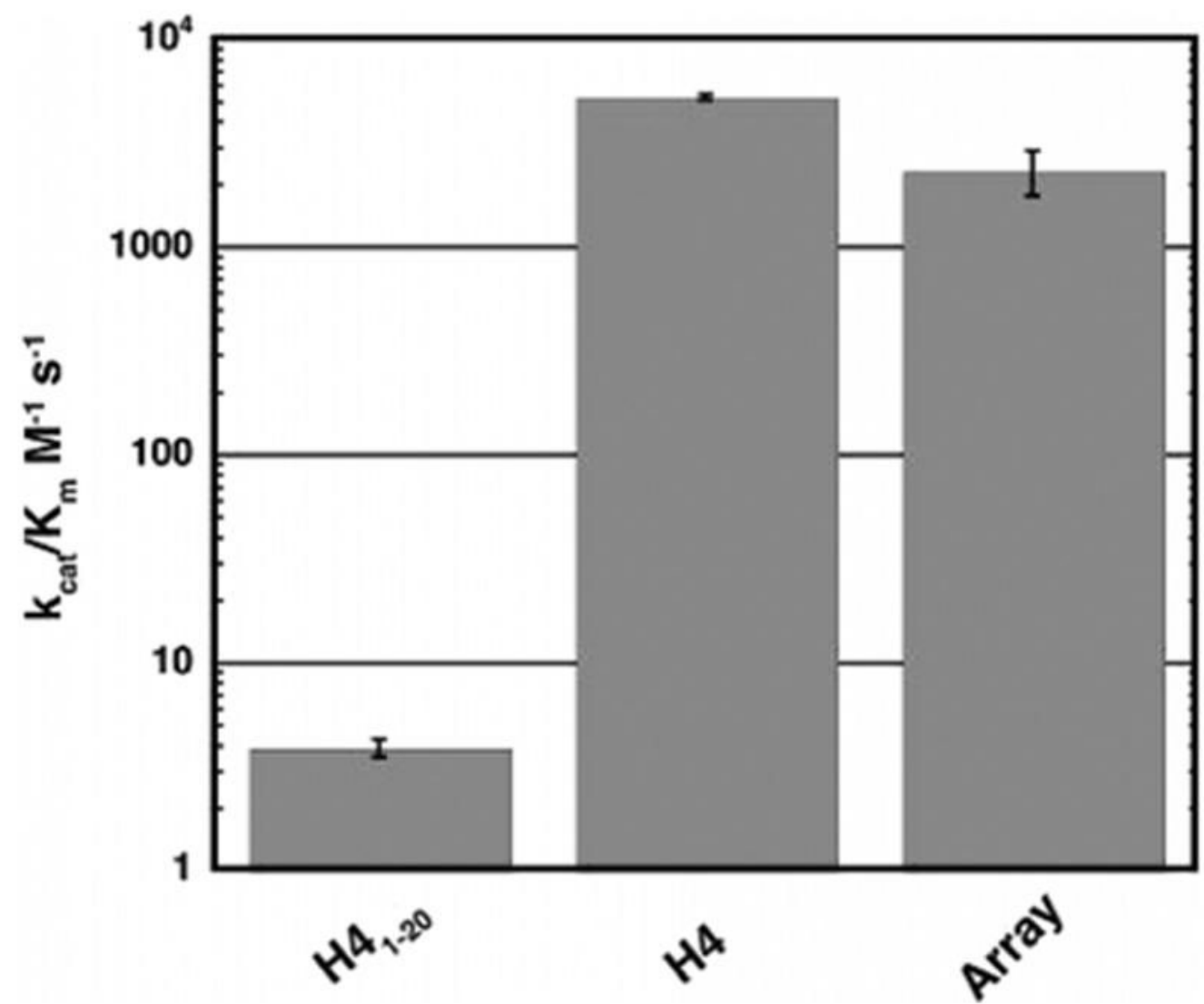

Figure 3.

Substrate specificity of Esa1. All reactions contain $1 \times$ TBA at pH 7.0 or $50 \mathrm{mM}$ Tris at $\mathrm{pH}$ 7.2, $1 \mathrm{mM}$ DTT, 75-100 $\mu \mathrm{M}$ acetyl-CoA, and 0.54-2 $\mu \mathrm{M}$ Esa1. Concentrations of peptide substrates in saturation curves were varied over a 10-fold range covering concentrations above and below the $K_{\mathrm{m}}$. Data were fitted to the Michaelis-Menten equation in Kaleidagraph to determine kinetic constants. The $k_{\text {cat }} / K_{\mathrm{m}}$ value for nucleosome arrays was collected under subsaturating conditions, and accordingly, the data were fitted to a linear equation where the slope is $k_{\text {cat }} / K_{\mathrm{m}}$. 


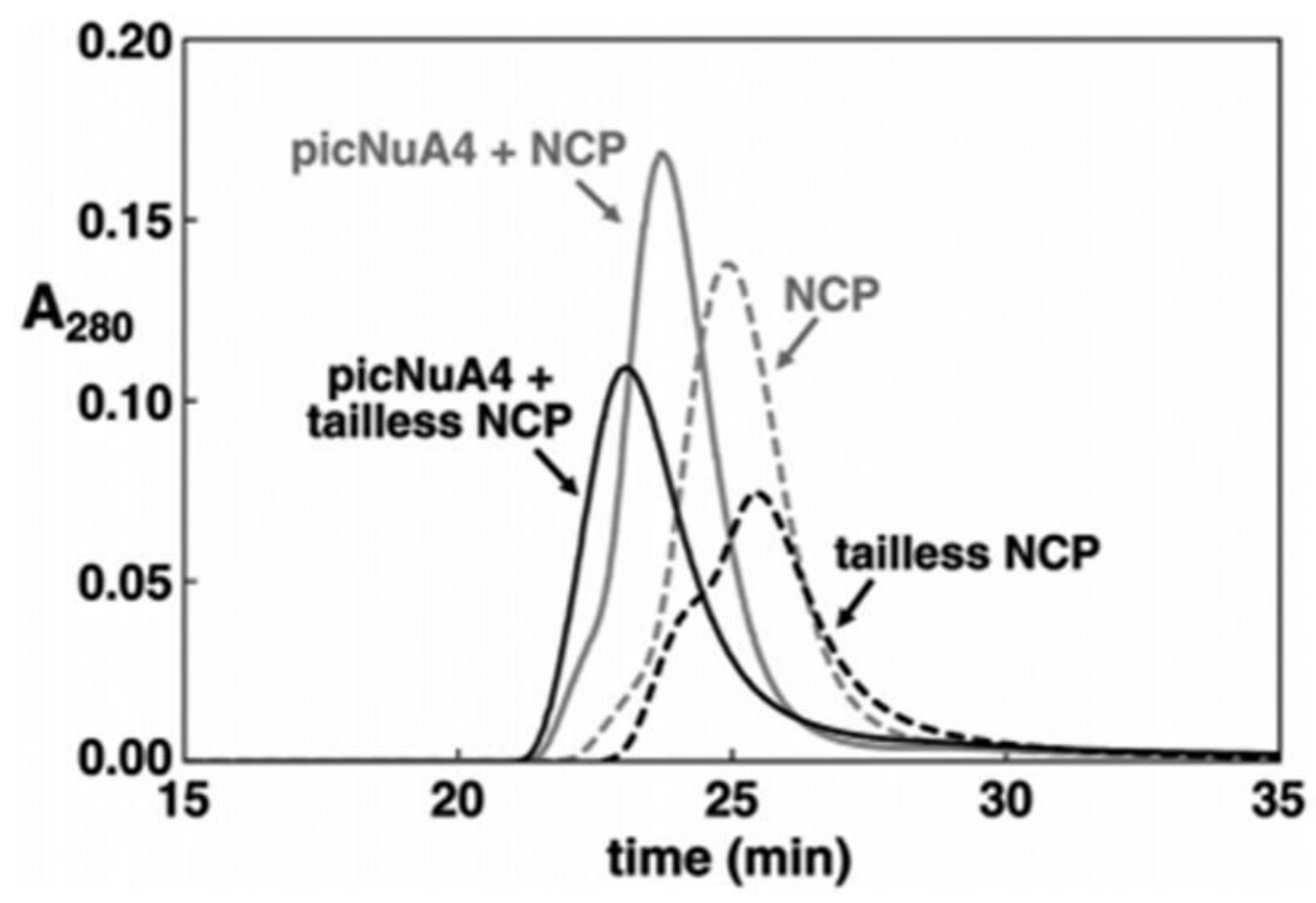

Figure 4.

Histone tails are not necessary for nucleosome binding. Gel-filtration chromatograms show picNuA4 incubated with tailed nucleosome core particles (gray line) or nucleosome core particles containing tail-less histones (black line). Also shown are nucleosome core particles containing full-length histone proteins in NCPs (dashed gray line) or tail-less histones in NCPs (dashed black line). The picNuA4 complex elutes at approximately $27 \mathrm{~min}$ (data not shown). The contents of the peaks were confirmed by SDS-PAGE (data not shown). 


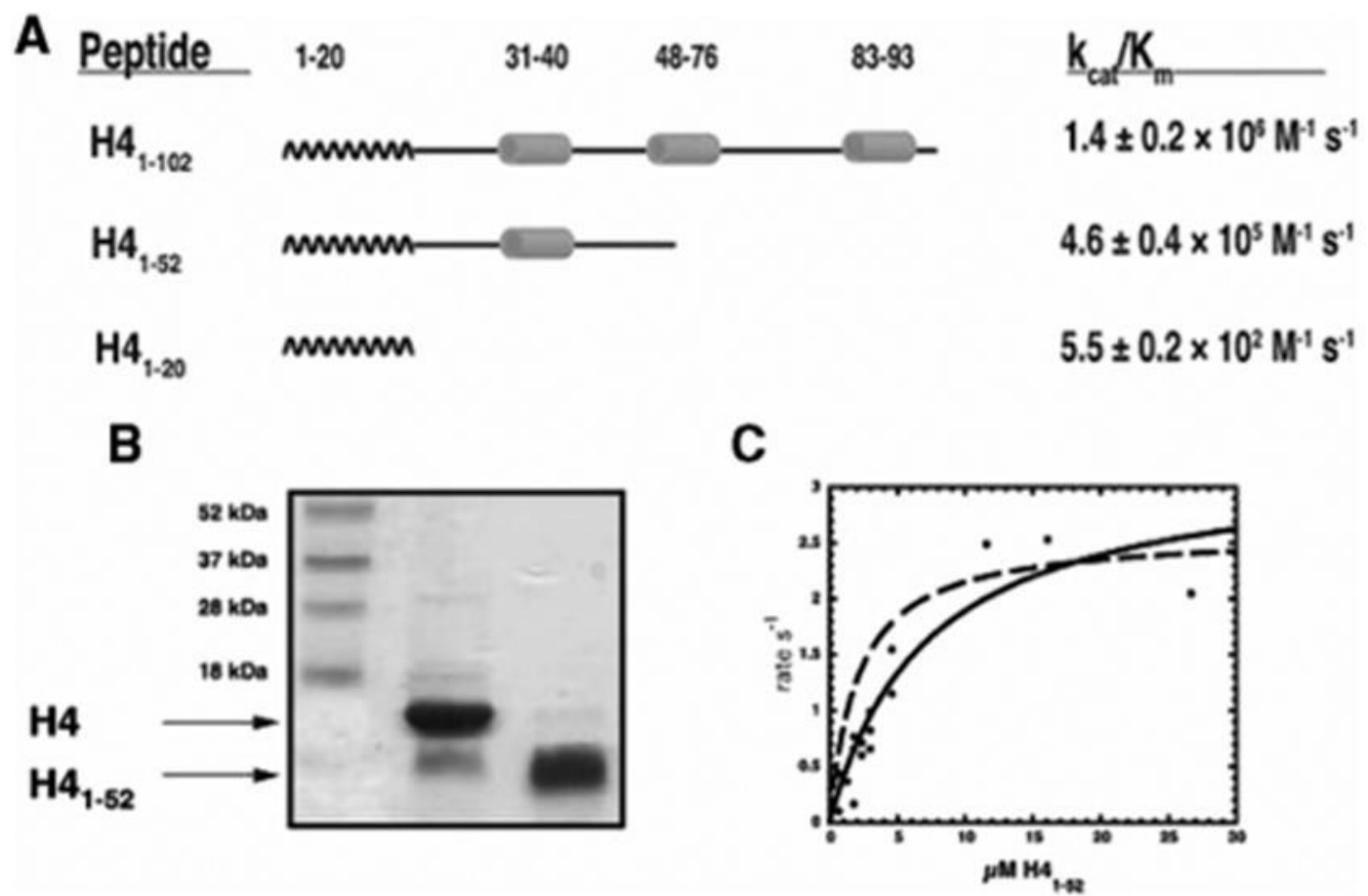

Figure 5.

picNuA4 requires residues 21-52 of $\mathrm{H} 4$ for efficient acetylation. (A) Diagram showing proteins/peptides used for identification of residues involved in the HFD interaction with picNuA4. The tail region is shown as a wavy line, and $\alpha$ helices in the core domain observed in nucleosome structures are shown as gray cylinders (38). (B) SDS-PAGE of purified H4 peptides. The $18 \%$ SDS-PAGE gel of histone $\mathrm{H}_{1-102}$ and $\mathrm{H} 4_{1-52}$. (C) Saturation curves for $\mathrm{H}_{1-52}$ and $\mathrm{H}_{1-102}$. The saturation curve for $\mathrm{H}_{1-52}$ was performed in $1 \times \mathrm{TBA}, 1 \mathrm{mM}$ DTT, $75 \mu \mathrm{M}$ acetyl-CoA, $0.018 \mu \mathrm{M}$ picNuA4, and $\mathrm{H}_{1-52}$ with a concentration from 0.57 to $26 \mu \mathrm{M}$ at $25{ }^{\circ} \mathrm{C}$. The $k_{\text {cat }}$ value was determined to be $3.3 \pm 0.4 \mathrm{~s}^{-1}$; the $k_{\mathrm{m}}$ value was $7.2 \pm 1.9 \mu \mathrm{M}$; and the $k_{\text {cat }} / K_{\mathrm{m}}$ value was $4.6 \pm 0.4 \times 10^{5} \mathrm{M}^{-1} \mathrm{~s}^{-1}$. The $\mathrm{H} 4_{1-102}$ saturation curve from Figure $1 \mathrm{~A}$ is shown as a broken line for a comparison. 

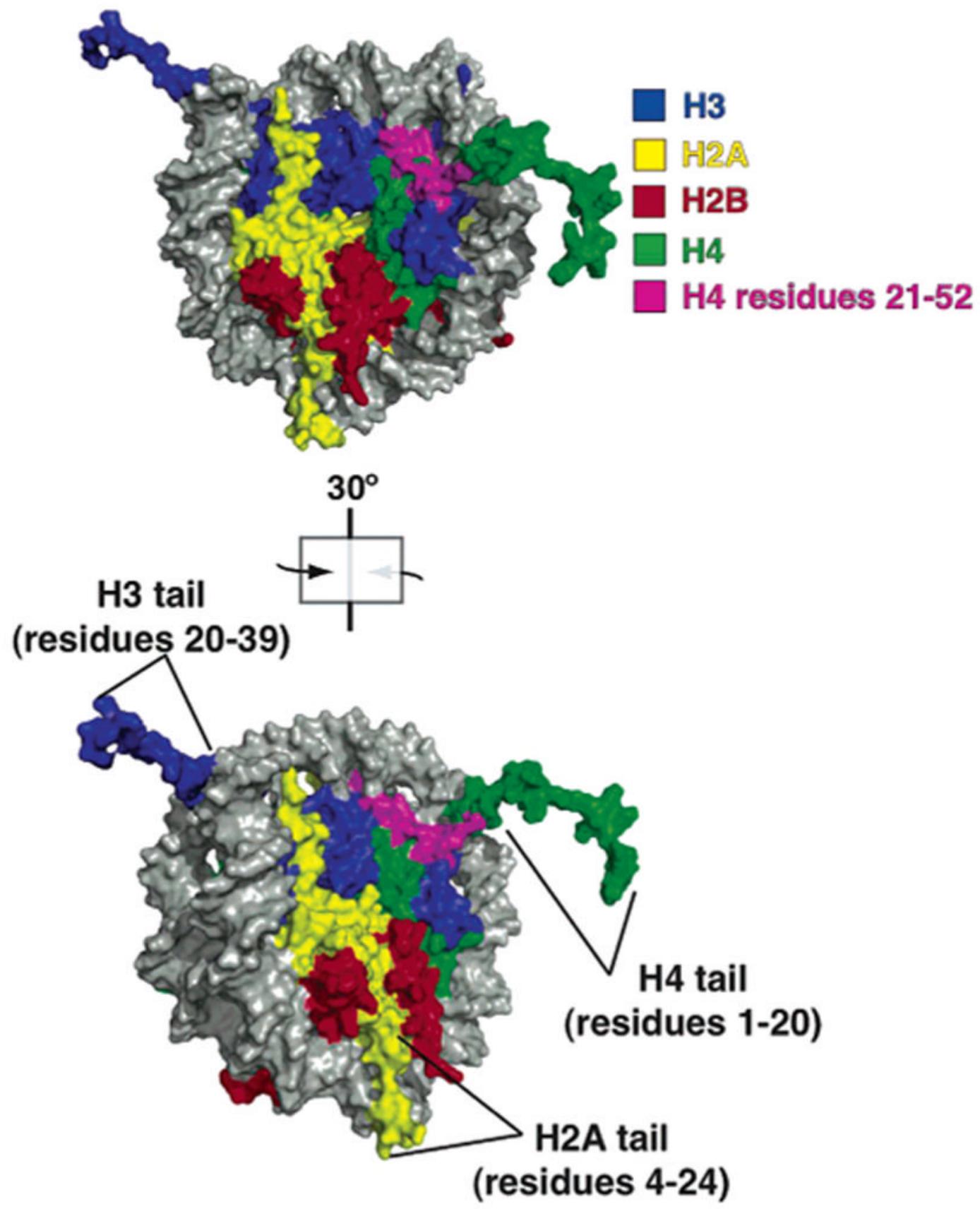

Figure 6.

Proposed picNuA4 interaction sites for histone $\mathrm{H} 4$ within the nucleosome. Illustration of the nucleosome structure showing the picNuA4 interaction site with the histone H4 HFD within the nucleosome. Esa1 and picNuA4 contact residues 21-52 within the HFD (magenta), which tethers the enzyme to the nucleosome, while the histone tail adopts the proper conformation to bind the active site. Nucleosome illustration created using MacPyMOL to render the nucleosome structure by Luger and co-workers and to draw in the histone $\mathrm{H} 4$ tail $(38,48)$. 


\section{Table 1}

Efficiency of picNuA4 on Tail-less Arrays

\begin{tabular}{lcc}
\hline array type & $\boldsymbol{k}_{\mathrm{cat}} / \boldsymbol{K}_{\text {avg }}$ & $\begin{array}{c}\text { fold difference compared to the wild } \\
\text { type }\end{array}$ \\
\hline wild type & $(8.0 \pm 0.1) \times 10^{6} \mathrm{M}^{-1} \mathrm{~s}^{-1}$ & 1 \\
$\Delta \mathrm{H} 3$ tail & $(9.6 \pm 0.1) \times 10^{6} \mathrm{M}^{-1} \mathrm{~s}^{-1}$ & 1.2 \\
$\Delta \mathrm{H} 2 \mathrm{~A}$ tail & $(9.0 \pm 0.2) \times 10^{6} \mathrm{M}^{-1} \mathrm{~s}^{-1}$ & 1.1 \\
$\Delta \mathrm{H} 2 \mathrm{~B}$ tail & $(7.2 \pm 0.1) \times 10^{6} \mathrm{M}^{-1} \mathrm{~s}^{-1}$ & 0.9 \\
$\Delta \mathrm{H} 4$ tail & $(1.0 \pm 0.2) \times 10^{5} \mathrm{M}^{-1} \mathrm{~s}^{-1}$ & 0.012 \\
tail-less & $<100 \mathrm{M}^{-1} \mathrm{~s}^{-1}$ & $1 \times 10^{-5}$ \\
\hline
\end{tabular}

